\title{
Stacking differences and similarities between a new and two old lapachol polymorphs
}

\author{
N. Di Benedetto', M.A. Martínez-Cabrera², M.A. Macías ${ }^{3}$, J. Barúa ${ }^{4}$ and L. Suescun ${ }^{1}$ \\ ${ }^{1}$ Cryssmat-Lab/DETEMA, Facultad de Química, Universidad de la República, Av. Gral.Flores 2124, Montevideo 11800, Uruguay, \\ ${ }^{2}$ Universidad Nacional de Asunción, Fac. de Ciencias Exactas y Naturales, Depto. de Biología, Área Química Orgánica de Productos \\ Naturales-LAREV, San Lorenzo Campus-UNA, Paraguay, \\ ${ }^{3}$ Department of Chemistry, Universidad de los Andes, Cra $1 N^{\circ} 18 A-12,111711$, Bogotá, Colombia, \\ ${ }^{4}$ Universidad Nacional de Asunción, Fac. de Ciencias Químicas, San Lorenzo Campus-UNA, Paraguay \\ ndibenedetto@fq.edu.uy
}

Lapachol (systematic name: 2-hydroxy-3-(3-methyl-but-2-enyl)-[1,4]naphtoquinone) is a 1,4-naphtoquinone, representative of a large class of natural compounds that exhibit a wide range of biological effects, acting as antibacterial, antifungal, antiparasitic, antiviral, antileishmanial and anticancer, among others [1]. The crystal structures of two polymorphs of lapachol LAPA I (triclinic $P \overline{1}$, a= 5.960(1), $\mathrm{b}=9.569(2), \mathrm{c}=10.679(2) \AA, \alpha=96.82(2), \beta=98.32(2)$ and $\left.\gamma=90.32(2)^{\circ}\right)$ and LAPA II (monoclinic $P 2_{1} / c, \mathrm{a}=6.035(1), \mathrm{b}=$ 9.427(2), $c=20.918(5) \AA$ and $\beta=98.27(2)^{\circ}$ ) were determined by Larsen et al. at $105 \mathrm{~K}$ [2]. In the course of our research on novel synthetic approaches and crystal structure determination of known and new derivatives of lapachol [3], crystals of a new lapachol polymorph were obtained. Lapachol (Fig. 1a) was obtained from an extract of Handroanthus heptaphyllus (Vell.) Mattos (pink trumpet tree or lapacho negro) and purified by recrystallization by slow evaporation from an $\mathrm{EtOH}: \mathrm{Et}_{2} \mathrm{O}$ mixture to obtain yellow crystalline plates that correspond, mostly, to LAPA II (monoclinic $P 2_{1} / c, a=6.0550(2), b=9.5769(2), c=21.2391(5) \AA$ and $\beta=$ $\left.98.2910(10)^{\circ}, \mathrm{T}=293 \mathrm{~K}\right)$. However, when lapachol was recrystallized from ethyl acetate, large yellow plates also containing lapachol molecules but arranged in a new crystalline form, were obtained. This new polymorph, LAPA III, also belongs to the monoclinic system, with space group $P 2_{1} / c$ and cell parameters $a=9.6134(5), b=6.0119(3), c=21.5464(11) \AA$ and $\beta=96.760(2)^{\circ}$ at $293 \mathrm{~K}$.

Lapachol molecules show the same conformation in the three structures and crystallize forming H-bonded dimers between nearby $\mathrm{OH}$ and ketone groups from two molecules related by an inversion center. In the three structures the dimers stack together in a staggered manner to form double layers of molecules with the butenyl moiety pointing outward. These layers seem to be very stable, since the $\mathrm{C}$ face of the unit cell is identical in the three compounds with $\mathrm{a} \approx 6.0(1), \mathrm{b} \approx 9.6(1) \AA$ and $\gamma \approx 90.0(4)^{\circ}$. The difference between them lies in the way successive layers stack to form the crystal. In the triclinic LAPA I all the layers stack in identical orientation with alternating butenyl residues from the bottom and top layers (Fig. 1b). The stacking in LAPA II, however, occurs with the next layer rotated $180^{\circ}$ and shifted $\mathrm{b} / 2$ respect to an axis parallel to $\mathrm{b}$ between the layers $(\mathrm{z}=1 / 2$ of the triclinic cell or $1 / 4$ of the monoclinic ones). This rotation axis transforms $b$ in the monoclinic axis of the cell and also introduces a c-glide plane normal to $b$. This makes the two parallel layers different along $\mathrm{c}$, so LAPA II exhibits a doubled c-axis. In addition to $\mathrm{a}, \mathrm{b}$ and $\gamma, \beta\left(\approx 98.3^{\circ}\right)$ is also conserved between both structures because the addition of symmetry requires no change in the relative position of the layers along b. LAPA III shows exactly the same relation with LAPA I except that the addition of symmetry occurs in the triclinic a-axis, so the conventional monoclinic unit cell given above shows a and b axes exchanged respect to LAPA I. Again, the addition of a $2{ }_{1}$ axis and a c-glide makes a-axis the unique one, and produces a unit cell that conserves a, b, $\gamma$ (as LAPA II) and the triclinic $\alpha$ angle $\left(\approx 96.7^{\circ}\right)$ transformed to $\beta$, and a doubled c-axis (Fig. 1c). Considering this, it is only the stacking of lapachol double layers what determines the polymorphic form. Hirshfeld surface analysis and intermolecular interaction energy calculations were performed to identify the main interlayer interactions to better explain the differences between the crystal structures of the three lapachol polymorphs.

(a)

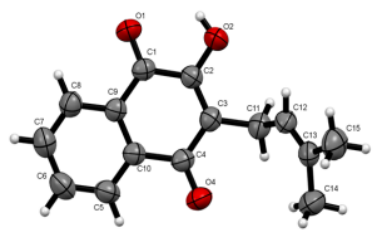

(b)

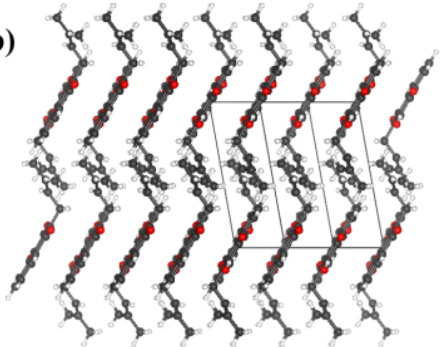

(c)

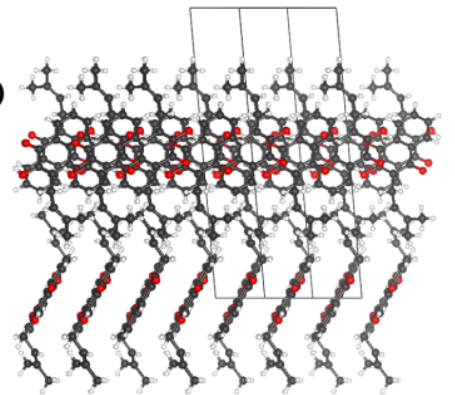

Figure 1. (a) Lapachol molecule in LAPA III, (b) layer stacking in LAPA I and (c) LAPA III after the cell transformation -b,a,c.

[1] Barbosa Coitinho et al. Prep. Biochem. Biotech. (2019). 49, 459-463.

[2] Larsen et al. Acta Cryst. (1992). C48, 2009-2013.

[3] M.A. Martínez-Cabrera et al. Acta Cryst. (2019). E75, 1362-1366.

Keywords: lapachol; polymorph; 1,4-napthoquinones

Acta Cryst. (2021), A77, C895 